\title{
Pedagogical Intervention in The Nursing Program for The Comprehensive Recognition of The Academic Performance of Students
}

\author{
Paula Andrea Duque* \\ Catholic University of Manizales, Colombia \\ Received: 睯: September 14, 2018; Published: 眥 September 21, 2018 \\ *Corresponding author: Paula Andrea Duque, Nursing Program, Catholic University of Manizales, Caldas, Colombia
}

\section{Mini Review}

Education is an intentional process of a social nature whose aims have varied from one era to another, from one culture to another, from one social class to another, and are largely determined by social, political, economic, philosophical systems, ethical and religious that have given rise to it. However, their common objectives are: socialization, the search for social adaptation of man to the group, its culture, its institutions; and the individualization, the promotion of the subject for its realization, according to its own aspirations. Therefore, its problematic is placed in the search of the balance between these two aspects complementary to each other, rather than contradictory; taking into account the individual and social character of man. Consequently, training must be conceived from the pedagogy with integrity to the challenges of teaching, research and social action that characterize the educational process of the higher level [1].

Faced with this premise the Educational Project of the Catholic University of Manizales is raised in permanent construction, defined by the same educational community and is oriented towards the development and humanization of knowledge, culture around the construction of new citizenship, drawing as a mission axis: The nursing program is no stranger to this feeling, so it is concerned with providing an integral education, which results in citizens committed to society and with the object of studying the discipline that is care, responding as ethical and political subjects, that seek the welfare of individuals, families and communities. The journey through the history of the nursing program has allowed the integration around the disciplinary training from the pedagogical scope, executing the teaching-learning processes, with a view of integral accompaniment, to the rescue of the protagonist role of the students, both in the appropriation and construction of knowledge [2]. In this dynamic the teaching is planned with a critical discourse, and a language of possibilities, a transforming teaching from the recognition of the other and not as a destroyer of human possibilities, in such a way that a different and promising future is projected in the students, to make them adopt an active role within the training spaces, as critics of the current problems, of the knowledge that is offered to them, and that they manage to get involved with the world with a critical stance. So, the educational processes are established with a pedagogical horizon around knowledge and practices, not as a simple teaching but as a complex event that brings together: thought, culture, language, art, values, texts, the methods, and that in no way reduces to the transmission of information, Tamayo [3].

Teaching has the purpose of learning and for this it is necessary to understand each other within communicative acts, where it is explicit and reasoned against the importance of the subject-subject relationship, taking into account which subject is the relationship with the context. The approach to teaching in the nursing program is carried out through a pedagogy proposal, which calls for transcending the reality of students through actions of alterity, which must be thought of and rethought as the first and fundamental responsibility of the educator, based on from the pedagogical interventions that emerge in the process of knowledge and experiences of training of autonomous subjects, capable of solving the different situations that arise in their adaptation [4]. Therefore, the objective is to develop critical pedagogical practices that allow students to understand the integral performance of the nursing program of the UCM, in order to enhance the leading role of students in the appropriation, construction and understanding of the training process [5].

\section{Strategies for the Development of Pedagogical Interven-} tion

The project arises and becomes relevant due to the need to articulate the purposes of higher education, the missional guidelines [6], the pedagogical model of the UCM, and the educational project of the nursing program, which raises as object of study "the care to the person ", and to make sense of discipline is contextualized in essence the meaning of caring, such as the nature of Nursing, and 
the fundamental criterion to distinguish it from other disciplines in the field of health, for which a logical pedagogical intervention is proposed, which allow coherence and meaning in learning, attending Freire [7], the immersion in pedagogical practice, must incorporate reflection, reasoning and reconstruction of the educational fact in and out of it, in this case tendiente to understand the acts of care through the articulation of nursing theory and the practice of care.

This dynamic has allowed the didactic transformation to a language of possibilities, from the teaching and specifically from the formation, allowing the recognition of the other and not as a destroyer of human tendencies; but projecting a different and promising future in the nursing students, from an active role within the training spaces, as proactive critics of the current health problems, as well as of the acts of care, through the educational tools that are offered, and that allows them to be involved in human needs and responses. The strategies focus on the student, thinking of an active participation in the learning process and a greater development of their reasoning, self-learning, self-evaluation, self-management and self-regulation capacities [8]. Favoring the development of a good critical and creative thinking, likewise is oriented as a provocation to the teacher, to select a variety of possibilities or appropriate educational strategies regarding learning, instruction, to reach the harmony established by the pedagogical model of the UCM, by what the following strategies establish from different dimensions:

\section{Development Dimension of the Person}

This dimension favors the promotion of creativity, the posing of problematizing situations and the strengthening of cognitive styles, benefits the development of critical and creative thinking, maximizes the utilization of students' abilities, encourages the implementation of attractive methods and motivators (according to the teaching-learning process in the field of nursing) and takes into account the multiplicity of situations and environments that students must face in their training [9].

\section{Individual and Collective Work Dimension}

Considering that learning occurs in the relationship between subjects, even though it has an individual aspect, we try to foresee activities that contemplate both the collective and the individual aspect, with the continuous support by the educational actors.

\section{Dimension of the Action}

It implies taking the action itself as an object of questioning to return to action, the realization of reports, trials, nursing situations and discussion groups have the objective of encouraging reflection on the action itself.

\section{Dimension of the Dialogue as Mediator of the Process.}

If the learning takes place in the relationship between the subjects, the dialogue becomes indispensable, since it is the one that can ensure the sharing of experiences, the discussion about the object of study, that is, the own learning with the other, so that dialogue exists It is necessary to know how to listen and respond to what the other tells us, recognizing him as the producer of his story [10].

\section{Dimension Pedagogical Structure}

Structure the process based on the protagonist of the student in the different moments of the learning activity, oriented from good teaching, part of the diagnosis of the preparation and development of the student, taking into account the individual differences in the undergraduate transit. Organize and direct the process of teaching and learning, from reflective positions of the student, which stimulate the development of their thinking and their cognitive independence. Stimulate the formation of concepts and the development of the logical processes of thought and the scope of the theoretical disciplinary level, to the extent that cognitive appropriation occurs.

Orient the motivation towards the study discipline and maintain its consistency.

\section{Develop the Need to Constantly Learn and Train on How to do it.}

Develop forms of activity and communication that allow favoring individual development, achieving an adequate interaction of the individual with the collective in the learning process. In this way, it is also coherent and encourages the actions of teachers and students with what is defined by Law 266 of 1996, in its chapter II [5], when it speaks of the nature and scope of professional practice in its definition and purpose: Nursing it is a liberal profession and a discipline of a social nature, whose subjects of attention are the person, the family and the community. The aim is to articulate the learning and the training process from a critical pedagogy as a way of reading reality, where the student is able to respond to social problems from a critical point of view, a respondent pedagogy, which implies conscious and responsible reflection, based on selfawareness training to achieve construction of meaning according to the personal experiences of students, aimed at the transformation social in favor of the most fragile, that is, a commitment to justice and equity, a critical pedagogy that can identify in the educational community, limitations and enhance capacities in such a way that it is the base artifact for self-improvement, having as elements fundamental active participation between teachers and students, permanent dialogue, humanization of pedagogical practices, transformation and contextualization. The intentionality in this proposal in relation to critical pedagogy is to create a language of possibilities, where problematizing teaching practices are generated, from a representative education that manages to provide guidelines that produce questioning thinking, leading the subjects to reflect on their own ideas, meanings and can transform educational environments into places of possibilities and capacities, where reflection and participatory action prevail, giving critical and rational meaning to learning processes [11].

\section{Methodological Strategy}

This educational proposal is based on the foundation of critical pedagogy and the possibilities of dialogue that can be promoted in the different training spaces, so that both teachers and students 
recognize themselves as builders of knowledge and as people in permanent training and that in such sense, both are able to appropriate, build and assess the quality of learning in order to bet on a comprehensive training and not only knowledge that can be applied from the profession in which they are linked, through:

a) The promotion of the participation of students in the training process.

b) Bringing knowledge to action, in such a way that its potential is recognized.

\section{c) Permanent conversations with students}

\section{Results Obtained}

Starting each corresponding academic period, the tutors present the students who do not reach the competences in each subject, which were initially intervened in terms of methods of study, time of dedication, role of student and process of university adaptation to those who are in the first semesters, each student was made a study method workshop and those considered relevant were referred to psychology through tutors for an integral education. When the students were approached, they found that they have family conflicts, so they become depressed and still have thoughts of not having an interest in living, (these were referred to psychology), among those addressed are students who belong to family welfare, who are He made special attention of study techniques and active listening as a method of pedagogical accompaniment.

The students in the meetings show that they are skeptical, very critical, and attentive to everything they may perceive as an arbitrary imposition that curbs their freedom of action and limits their freedom of thought and opinion. They are vehement with determination and initiative, dynamism and creativity capable of transforming societies. On the other hand is also in the students the disenchantment and indifference in front of their daily problems, their home of their institution and their environment, their values are not manifested in their acts, are considered ethereal and incoherent, give priority to the fun, prefer the lightness of life easy, hasty and entertaining, are content to meet the minimum requirements for the fulfillment of their responsibilities, prefer the personal benefit to the common good. In the second period of 2017 and first of 2018, approximately 170 students attended between repeaters and special cases. Special cases have been referred to psychology of medical services of the UCM for pedagogical accompaniment to which special attention was paid to study techniques and active listening as a method of pedagogical accompaniment.

\section{Conclusion}

a) The first and second semester students need an adaptation of university adaptation, due to the uncertainty and the acceptance of the university role and what the training means discipline, which creates difficulties that destabilize the student but that must be solved along the way.

b) There are situations in the students that require only the accompaniment of the tutor, others need advice on study habits and there is another number that requires psychosocial support, to reach competences, but the most important thing is to achieve self-recognition and preferences in the lifetime.

c) The teaching processes must be developed not only from the knowledge of the different subjects, it also requires the pedagogical and disciplinary knowledge to provide an education that really aims to fulfill the missionary objectives and results in the formation of citizens committed to themselves with the profession and with society.

d) Students have as an imaginary that the accompaniment is to intervene so that their grades increase in numerical figures, an issue that permeates even in the teachers, which may be related to the institutional evaluation process.

\section{References}

1. Carroll L (1995) Alice in Wonderland. Madrid: Siruela.

2. Castrillón A (2008) thinking about the training of future professionals in Latin America. invest. educ enferm 26: 2.

3. Tamayo LA (2007) Trends in Pedagogy in Colombia. Latin America Students. Education. Manizales, 3 (1): 69.

4. Freire P (1971) Pedagogy of the Oppressed City: Studio 3 Latin America.

5. Gorrochotegui A (2006) Be a university professor. Reflections about university teaching. Active Awareness 11: 114-115.

6. Law 266/1996, by which the nursing profession in Colombia is regulated and other provisions are enacted.

7. Muñoz Y, Coral R, Moreno P, Pinilla D, Suarez R (2009) Meaning of humanized care in graduates of the faculty of nursing. Reflection article Repertory magazine of medicine and surgery 18(254).

8. Mounier E (1980) Personalism Buenos Aires: University Press of Buenos Aires.

9. Patiño G (2006) The observation of pedagogical practice in the training of future teachers. Pedagogy and knowledge, 24: 27-31.

10. (2013) Educational Institutional Project Universidad Católica de Manizales, p. 29.

11. Catholic University of Manizales (2007-2013) Teleological Framework of the Catholic University of Manizales. Manizales: Centro Editorial UCM. 


\section{ISSN: 2574-1241}

DOI: $10.26717 / B J S T R .2018 .09 .001770$

Paula Andrea Duque. Biomed J Sci \& Tech Res

(c) (i) This work is licensed under Creative

Submission Link: https://biomedres.us/submit-manuscript.php

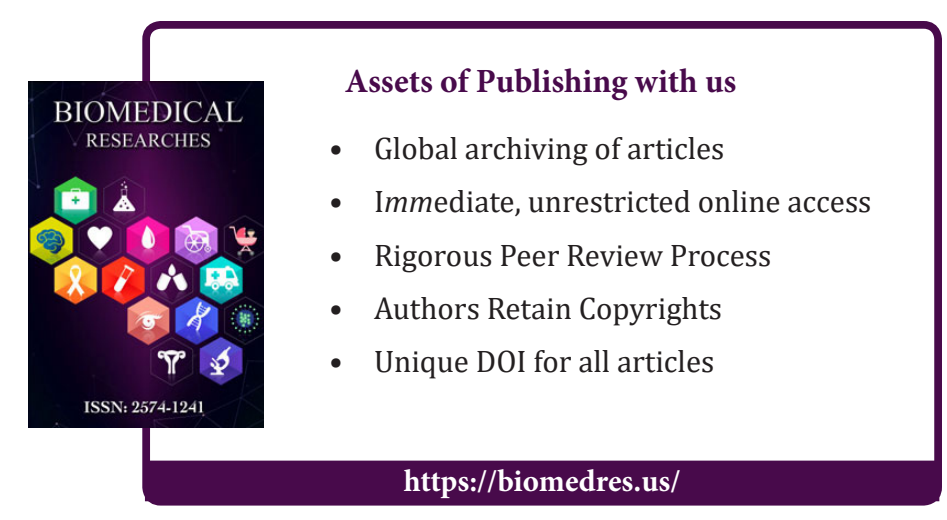

